\title{
A SEXUALIDADE INVISÍVEL OU OCULTA NA ENFERMAGEM?
}

\author{
INVISIBLE OR HIDDEN SEXUALITY IN NURSING
}

\section{LA SEXUALIDAD INVISIBLE U OCULTA EN ENFERMERÍA?}

Lúcia Beatriz Ressel *

Dulce Maria Rosa Gualda**

Ressel LB, Gualda DMR. A sexualidade invisivel ou oculta na enfermagem? Rev Esc Enferm USP 2002; 36(1): 75-79.

\section{RESUMO}

Este artigo é uma reflexão, que permeia a temática da invisibilidade e/ ou ocultamento da sexualidade na prática do cuidar da enfermeira, remetendo a questões que passam pela orientação desta postura, como se criou e o quê a mantém. A abordagem apresentada permite afirmar que o tema deve transcender o informativo técnico e, ao mesmo tempo, ser revelado na diversidade cultural das enfermeiras, oportunizando uma instrumentalização para o "ser" e o "fazer" da enfermagem, proporcionando uma vivência qualitativamente mais significativa.

PALAVRAS-CHAVE: Sexualidade. Enfermeira. Cultura.

\begin{abstract}
This article is a reflection which pervades the theme about invisibility or hiding of sexuality in the nursing care practice, or besides, of the nurses themselves, leading to questions which hold this bearing, how it was created and what maintains it. The approach presented here permits to assure that this theme goes beyond technical informative itself and, at the same time, is revealed in the nurses's cultural diverseness, giving the opportunity to instrument people for the being and the doing in nurging which provides an experience of life much more qualitatively meaningful.
\end{abstract}

KEYWORDS: Sexuality. Nurse. Culture.

\section{RESUMEN}

Este articulo es una reflexión, que pasa por la temática de la invisibilidad y/u ocultamiento de la sexualidad en la práctica del cuidar de enfermería, remitiendo a cuestiones que atraviesan por la orientación de esta postura, como se crió y el que la mantiene. El abordaje presentado permite afirmar que el tema debe trascender el informativo técnico y, al mismo tiempo, ser revelado en la diversidad cultural de las enfermeras, oportunizando una instrumentalización para el "ser" y el " "hacer" de la enfermeria, proporcionando una vivencia cualitativamente más significativa.

PALABRAS CLAVE: Sexualidad. Enfermera. Cultura.

Doutoranda do Programa Interunidades de Doutoramento da EEUSP. Enfermeira, Prof do Departamento de Enfermagem da Universidade Federal de Santa Maria - UFSM. Santa Maria, e-mail: 1bressel@bol.com.br. Profa. Dra., do Departamento ** de Enfermagem Materno-Infantil e Psiquiátrica da EEUSP. 


\section{INTRODUÇÃO}

A invisibilidade e o ocultamento de alguns temas trazem, por si só, uma significação especial. Isto acontece em relação ao tema da sexualidade na formação e na prática da enfermeira.

Há muito tempo esse assunto tem chamado a minha atenção. Em parte pela vivência profissional, como docente da disciplina Enfermagem MaternoInfantil na Universidade Federal de Santa Maria, onde assisto mulheres no Programa de Atenção Integral à Saúde da Mulher (PAISM) em ações de pré-natal e planejamento familiar, de onde emergem grande quantidade de questões relativas à sexualidade feminina e que impulsionam minha constante reflexão da vivência de ser mulher, semelhantemente, as tantas mulheres a quem assisto, e que culturalmente são singulares.

Isso induziu-me no mestrado (em Extensão Rural, na UFSM) a realizar um trabalho de campo, que vinculasse a questão da cultura e da sexualidade da mulher rural, culminando na dissertação intitulada "A cultura como mediadora da sexualidade da mulher rural".

Se, anteriormente, a essa vivência sentia inquietações acerca do tema, que, naturalmente, já é bastante polêmico e mantém-se no ocultamento das discussões acadêmicas, após esta experiência, meus questionamentos (que há muito tempo superaram o limiar pessoal) transcenderam o espaço específico do "ser enfermeira", e de como se dá o enfrentamento e a vivência das questões da sexualidade expressadas a todo momento no nosso cotidiano profissional.

Por outro lado, não são as questões teóricas e biologicistas relativas à genitalidade, que suscitam minha atenção nesta área, mas a representação cultural que elas trazem e que estão embutidas em nossos discursos, em nossas atitudes, posturas, olhares, silêncios, enfim, o comportamento como um todo, e que se reproduz constantemente na formação das enfermeiras.

Na enfermagem, um sinal de que a sexualidade é tratada como um tabu é a própria carência de estudos, de discussões e de reflexões realizadas em nível acadêmico e na própria prática profissional, além do que, quando viabilizadas, aparecem numa perspectiva patologizante limitada ao coito, ao ato sexual como fonte de risco e não de prazer ${ }^{(1-4)}$

Embora ela esteja presente em todos os momentos vividos pela enfermeira, é, ainda, mantida silenciosa, encoberta ou na invisibilidade. Esta idéia remete-me a questões que buscam o entendimento dessa invisibilidade. Portanto, pergunto: o que poderia orientar essa postura, que parece vitalícia, como se criou e mantém-se ao longo de nossa formação e prática?
Essas indagações não são exclusividade minha, outros pesquisadores já as fizeram e, a seguir, aponto seus trabalhos, mas antes disso gostaria de explicar porque optei por utilizar neste texto o termo enfermeira(s), já citado algumas vezes, como um substantivo do gênero feminino: primeiro, por estar referindo-me, especificamente, à vivência da sexualidade feminina na prática do cuidado de enfermagem e, segundo, porque na enfermagem o maior contingente de enfermeiros são mulheres, o que torna nossa profissão sexualmente feminina, sendo que a própria designação gramatical no gênero masculino traz, no meu entender, e em concordância com Polak ${ }^{(5)}$, uma marca da ideologia patriarcal que eu não gostaria de reforçar neste texto. Entendo, também, que, embora específico à vivência da enfermeira, esse texto pode trazer dados interessantes a outras áreas e espaços de cuidado da saúde.

\section{A vivência da sexualidade na prática do cuidado da enfermagem}

Alguns estudos têm surgido, principalmente, na última década, dentro da enfermagem, no sentido de trazer reflexões, que induzam à transferência desse tema, do ocultamento e da invisibilidade para um fórum de discussão límpido e transparente.

Junto a eles vêm algumas respostas na tentativa de ajudar a entendermos o quadro que vivemos neste momento na enfermagem e na própria área da saúde como um todo, possibilitando condições para uma reorientação. Quem sabe isso já não é um prenúncio para tal, já que estamos no final do século XX e mudança de milênio?

Um desses trabalhos que considero de pertinência esclarecedora e motivadora de mudanças é a tese, que trata sobre os mecanismos de interdição da sexualidade feminina na formação da enfermeira (2).

Nessa tese ela reconstrói, historicamente, por meio da memória das enfermeiras, como se deu o começo das interdições que disciplinaram as representações da sexualidade desse grupo social, mostrando como foi (e ainda é) reproduzido esse caráter de assexualidade na enfermagem pelas próprias enfermeiras.

A referida autora inicia o seu texto reportandose à questão de ser mulher e o aspecto do cuidar que a ela é determinado dentro da lógica da sociedade ocidental moderna.

Sobral(2) salienta que o verbo cuidar é um verbo historicamente feminino, ocorrendo no espaço privado, tendo aí uma dimensão que atinge, através do toque, a expressão do prazer, do sensual, do erótico, da troca de sensações e de sentimentos, naturalmente inerentes à mulher, como um legado de cultura de gênero, no entanto, limitado ao âmbito do privado, do doméstico, pois é, sobretudo, relativo à intimidade. 
Ela diz que, no momento em que a enfermagem, como profissão, possibilitou à mulher sair da esfera do privado para a vida pública, o seu comportamento sensual e erótico, natural da sexualidade, porém pertencente ao domínio íntimo, começou a sofrer interdições, com finalidade de controle.

A mulher, então, investida da personagem enfermeira deveria conter seu próprio corpo, controlar emoções, asfixiar a sensibilidade, para que pudesse manipular o corpo do outro.

Assim, Sobral(2) refere-se à enfermagem como uma instituição social, que possui uma autorização implícita social em suas normas culturais, permitindo a manipulação do corpo do outro. Essa manipulação dá-se no cuidado de enfermagem, por intermédio do toque que, nesta situação, investe-se de poder (de quem está tocando e de quem está sendo submetido a ele). Esse poder é transmitido por meio dos discursos existentes na formação e na prática dos enfermeiros e da própria técnica utilizada no cuidado.

Os discursos excluem o erótico, o sensual e são carregados de preconceitos, agravando mitos e tabus, criando um clima de proibição sobre o assunto, despertando dúvidas e incertezas, as quais se sobrepõem ao não dito, ao não expressado verbalmente. Isso faz com que cada um haja de acordo com suas pré-concepções, gerando, muitas vezes, constrangimentos, sentimentos de vergonha, de culpa e de hostilidade, tanto para a enfermeira quanto para o outro, com quem ela está se interrelacionando no momento do cuidado(2).

Quanto à técnica, Sobral (2) diz, em concordância com Loyola(6), que a mesma é um instrumento foucaultiano de docilização dos corpos, onde é possível manipular o corpo do outro sem a possibilidade de prazer, através da exaltação aos passos da técnica e ao rigorismo que a compõe. E é na massificação das tarefas, na rigidez das regras e dos rituais, no frenético ritmo de trabalho que a enfermeira desempenha seu personagem, não como a mulher, mas como a profissional.

Neste sentido, apoio-me na explicação de Goffman(7), que utiliza a metáfora teatral como estrutura de sua exposição, ou seja, todo homem em qualquer situação social, apresenta-se diante de seus semelhantes, tenta dirigir e dominar as impressões que se possam ter dele, empregando certas técnicas para sustentação de seu desempenho, tal qual um ator que representa um personagem diante do público.

Assim, num palco (hospital limpo, asséptico, neutro, acrítico, impessoal) ela (a mulher) se investe de um personagem (enfermeira), cuja atuação esperada deve ser perfeita, porém nos bastidores ela pode novamente ser, agir, sentir, expressando sua sexualidade como mulher.
Dessa forma, a robotização de atitudes, a impessoalidade, a disciplina, a massificação de tarefas, o controle dos gestos, dos sentimentos, das emoções e do seu próprio corpo dão-se como estratégias para o ato encenado.

E, assim, a denegação de sua sexualidade é transmitida, vitaliciando-se na extensão da prática e na formação da enfermeira nas pequenas e corriqueiras situações da vida desta, tais como: o modo de vestir, o que pode ou não usar, como pentear o cabelo, o comprimento deste, a permissão para o uso e o tipo de jóia, o uso ou não de maquiagem, de esmalte nas unhas e o comprimento destas, o modo de andar nos corredores do hospital, a altura do salto do calçado, o tom de voz, como se dirigir numa conversa com o médico, sua postura e comportamento(8).

Essa disciplinarização, certamente, beneficia alguma parte envolvida na cena. Em seu trabalho, Lunardi(8) questiona a quem cabe esse beneficio. Será que a "docilização das enfermeiras" vem em beneficio dos pacientes, da instituição, do grupo social das enfermeiras?

Nesse sentido, Sobra (2) acrescenta que a instituição hospitalar tem, na sua organização, a possibilidade de explorar, ao máximo, a "tecnificação" da enfermagem num processo de dominação e controle político-econômico.

Essa idéia é referida, também, por Lopes(9), quando menciona que, no hospital, os espaços e as práticas sustentam-se sob uma espécie de "código de ação" e, nos serviços de enfermagem, pode ser percebido, nitidamente, esse recurso normatizador (exemplificado anteriormente por Lunardi(8), através do controle das qualidades morais e dos rituais (técnicas) exercidos na sua prática.

Desse pensamento comungam, também, Paskulin(10) , assim como Sobral'", salientando que tais ações disciplinadoras estendem-se na formação das enfermeiras para além do aspecto profissional, atingindo a vida pessoal e perpetuando-se nas interrelações, principalmente, no controle dos aspectos da sexualidade, produzindo e reproduzindo enfermeiras deserotizadas com possibilidades de prazer proibidos e voltadas para o compromisso do dever e do trabalho.

As estratégias de dominação, que são desenvolvidas por meio das regras, da disciplina, da "tarefação" e da exaltação da técnica, fazem com que a enfermeira distancie-se de um exercício profissional criativo e sensivel e, nesta condição, ela deixa de utilizar terapeuticamente a sexualidade dos corpos e de harmonizar seus sentidos(2).

É muito comum, também, ouvirmos as enfermeiras referirem que tratam as questões da sexualidade, as quais envolvem os sujeitos de seus cuidados, de forma "natural" e/ou com "seriedade". 
No entanto, aí, já expressam todo seu pudor e o controle de suas emoções e sentimentos para não demonstrarem o constrangimento, ao lidarem com o corpo nu e por manipularem as chamadas "partes intimas". Existe uma negação da realidade para ocultar suas dificuldades nesta área(2-5)

Durante muito tempo, essa dificuldade foi fortalecida através da utilização de manequins (femininas) para o treinamento da manipulação do corpo do outro. Os manequins não sentem dor, não reclamam, não expressam reações sexuais, mas quando esse treinamento dava-se em corpos reais era dada prioridade ao cuidado (com seriedade) ao corpo de mulheres, sendo que o dos homens era somente quando se encontravam inconscientes, porque assim eles não reagiriam como homens e não seria "perigoso").

Seguindo nesta linha de pensamento, Sobral(2) remete-nos a uma questão: qual a relação entre pudor e cuidado com seriedade e naturalidade?

Entendo que o constrangimento e o pudor existem, mas são encobertos pela técnica com "seriedade e naturalidade". E a autora confirma isso, salientando que inexistem cartilhas de orientação ou técnicas de enfermagem que ensinem como se deve proceder nessas situações, levando-nos à privação de discutir essa questão. Na realidade o que se dá são soluções pessoais. Inseguras, muitas vezes, alienadas, outras tantas, mas descomprometidas com o sujeito do cuidado em muitas.

Essa idéia reforça, novamente, a necessidade de desvelarmos esse tema na enfermagem. Cabe ainda pontuar neste texto o trabalho que vem somar ao dito até aqui sobre como a sexualidade vem sendo tratada pela enfermeira ${ }^{(12)}$.

Ao discutir sobre o corpo da enfermeira como instrumento do cuidado, essas autoras ilustram em um dos seus capítulos a questão da sexualidade ausente nas representações que as enfermeiras fazem de si mesmas. Elas mostram como o sexo é, ainda, um tabu para a maioria das enfermeiras, o que é reforçado pela projeção social de uma imagem da enfermeira como anjo assexuado.

Elas sustentam, neste trabalho, semelhantemente à Sobral(2), que a sexualidade das enfermeiras está presente no ato de cuidar, através do toque e do prazer de cuidar e que a essência da sexualidade é a própria noção do prazer: o prazer de cuidar, de se preocupar, de fazer coisas para o outro, com o outro e pelo outro.

Estas autoras afirmam que as enfermeiras expressam sua sexualidade, permanentemente, através dos gestos, dos movimentos corporais e nas entrelinhas implícitas do que foi verbalizado ou não.

Porém, continuam as autoras, as enfermeiras tendem a omitir as lembranças da sexualidade, ou seja, a consciência de sua própria sexualidade, e isso pode afetar seu equilíbrio emocional, trazendo, em nivel pessoal, dificuldades para resolução de seus próprios conflitos, que, indiretamente, estende-se aos sujeitos de seus cuidados.

Neste sentido, elas afirmam que a sexualidade necessita ser tratada como um assunto de estudo na enfermagem e como um fenômeno essencialmente inerente a todo ser humano.

Para finalizar, utilizo o pensamento que conclamam as enfermeiras para assumir a marca feminina de ser e estar com gente, construindo e alimentando a capacidade de desenvolver e ampliar a sensibilidade e de exercitar a sexualidade como uma das características do que há de mais humano em nós(11). Para tanto, teremos que enfrentar um grande e dificil desafio que é o de "desconstruir" o que foi internalizado pela própria cultura de valores e de normas da moral religiosa, onde a enfermagem apossou-se de rituais de neutralização dos corpos erotizados, procurando esconder o corpo feminino, por intermédio do uso de uniformes, utilizando cerimoniais que distanciaram as possibilidades das relações sociais e impossibilitaram o prazer.

\section{COMENTÁRIOS FINAIS}

As reflexões apontadas até aqui, mostram de que forma a sexualidade vem sendo vivenciada pelas enfermeiras, através de uma espécie de invisibilidade, ou como dizem, por uma "cortina de fumaça", que oblitera a visão desviando-a deliberadamente, deste assunto, ocultando-o, ou quando "visto", sob uma perspectiva patologizante de risco ou dano à saúde ${ }^{(12)}$.

Isso traduz minha preocupação de como está desenvolvendo-se a formação da enfermeira. Se estão sendo reforçados esse ocultamento e essa invisibilidade, mantendo-se uma lacuna, ou se perpetuando a limitação da criatividade, da sensibilidade e da liberdade.

E, quando me refiro a formação da enfermeira, não me restrinjo ao período acadêmico, mas a estendo ao dia-a-dia da enfermeira, que se mantém contínua e dinamicamente em formação, e cujo exercício da prática é um exemplo vivo para a aprendizagem acadêmica.

Portanto, me reporto, de uma maneira especial, â enfermeira de campo, que vive no seu cotidiano situações tais quais as descritas, anteriormente, reagindo a elas, de forma específica, mas que marcam o conjunto do grupo social a que pertence.

Esta explanação, que entendo como uma reflexão inicial, traz subsídios de como vem sendo contemplada a sexualidade na prática do cuidado das enfermeiras. Essa abordagem permite-me insistir que esse tema deva 
transcender o informativo técnico e, ao mesmo tempo, ser revelado na diversidade cultural das enfermeiras, proporcionando uma instrumentalização para o "ser" e o "fazer" da enfermeira, que lhe possibilite uma vivência, qualitativamente mais significativa, mais sensivel e mais liberta.

Respondo neste final de texto ao questionamento que o intitula. Entendo que a sexualidade é tratada pelas enfermeiras como uma questão invisivel e, ao mesmo tempo, oculta.

Invisivel enquanto, ainda, nem é visionada sua possibilidade de existência, pois não a vemos e nem temos conhecimento e ignoramos, no bom sentido da palavra, essa questão em nossa prática. E oculta, quando sabemos que ela existe, mas por condições e motivos "n" a mantemos escondida, não a manifestamos e nem permitimos sua revelação.

Essa falta de condições ou motivos é ímpar e, sem dúvida, está relacionada à diversidade cultural, que promove nossa construção como enfermeiras, o que implica, portanto, na necessidade de produzir estudos para seu entendimento e, quiçá um novo direcionamento para nossa prática de enfermagem.
(9) Lopes MJ. O sexo no hospital. In: Lopes MJ, Meyer DE, Waldow VR. organizadores. Gênero e saúde. Porto Alegre: Artes Médicas, 1996. p.

(10) Paskulin LMG. O saber e o fazer como processo educativo para a enfermeira. In: Meyer DE, Waldow VR, Lopes MJ. Marcos da diversidade: saberes e fazeres da enfermagem contemporânea. Porto Alegre: Artes Médicas; 1998. p.

(11) Sobral VRS, Miranda CML, Figueiredo NMA, Santos I. $O$ que escondiam nossos corpos escondidos pelos uniformes? Rev Enferm UFRJ 1995; 3(2): 244-248.

(12) Figueiredo NMA, Carvalho V. O corpo da enfermeira como instrumento do cuidado. Rio de Janeiro: Revinter; 1999.

\section{REFERÊNCIAS BIBLIOGRÁFICAS}

(1) Egry EY, Fonseca RMGS, Oliveira MAC. O estudante de enfermagem frente a questão da sexualidade humana, nos aspectos referentes à contracepção. Rev Gaúcha Enferm 1990; 11(1): 47-51.

(2) Sobral VRS. A purgação do desejo: memórias de enfermeiras. (Tese). Rio de Janeiro (RJ): Escola de Enfermagem Anna Nery da UFRJ; 1994.

(3) Teixeira ER. Desejo e a necessidade no cuidado com o corpo: uma perspectiva estética na prática de enfermagem. (Tese) Rio de Janeiro (RJ): Escola de Enfermagem Anna Nery da UFRJ; 1998.

(4) Diaz M, Diaz J. Qualidade de atenção en saúde sexual e reprodutiva: estratégias para mudanças. In: Galvão L, Diaz J. organizadores. Saúde sexual e reprodutiva no Brasil. São Paulo: Hucitec; 1999. p.

(5) Polak YNS. A corporeidade como resgate do humano na enfermagem. Pelotas: Universitária/UFPel; 1997.

(6) Loyola CMD. Os doce (i) s corpos do hospital - as enfermeiras e o poder institucional na estrutura hospitalar. [Dissertação]. Rio de Janeiro (RJ): Universidade Federal do Rio de Janeiro; 1984.

(7) Goffman E. A representação do eu na vida cotidiana. 8 ed. Petrópolis: Vozes; 1989.

\section{Artigo recebido em 09/05/01}

\section{Artigo aprovado em 31/01/02}

(8) Lunardi VL. Repensando a formação da enfermeira. Rev Enferm UERJ 1994; 2(2): 221-224. 